\title{
HoNOS in long-stay patients with learning disabilities
}

\author{
Olakunle Ashaye, George Mathew and Elizabeth Rigby
}

\begin{abstract}
This study, assessed 63 older, long-stay, learning disabled patients, the Health of the Nation Outcome Scales (HoNOS) highlighted the expected problems in areas of cognition, physical illnesses or disabilities, relationships and activities of daily living. No significant changes were observed in the problems assessed using the HoNOS over a six-month period in this group of patients with relatively stable health problems and needs. HoNOS proved to be useful in identifying some expected problems. However, further studies are needed to assess its sensitivity to changes secondary to improvement or worsening of problems along with wider use to see if its brevity allows it to give sufficient detail on the problems of persons with learning disabilitios.
\end{abstract}

Targets of heatlh care set by the United Kingdom Government resulted in the Royal College of Psychiatrists' Research Unit developing a set of 12 scales designed to monitor mental health: the Health of the Nation Outcome Scales (HoNOS; Wing et al, 1994). As a simple and concise instrument, it is intended to be used by various cadres of mental health professionals and comes with a glossary to enable easy interpretation of scores.

As a new instrument, literature on HoNOS is scarce, but reports from the few studies that have been published suggest benefits of this concise, brief set of scales to monitor health and social functioning, although they also identify problems in its use for certain groups of patients with mental health problems or learning disabilities (Allan \& McGonagle, 1997; Ashaye et al 1997).

Jenkins et al (1994) highlighted the need for outcome indicators in elderly people with learning disabilities, especially as longevity is increasing in this group of patients, to enable clinicians, planners, purchasers and policy-makers to monitor and evaluate the impact of health and social care. They suggested a multiaxial approach to assessing physical health, cognitive abilities, mental health, social stresses and social disabilities. The 12 HoNOS covering behavioural, symptomatic and social problems address most of the identified problems needing assessment.

The 12 HoNOS rate problems with overactivity self-injury, substance misuse, cognition, physical illness, psychotic symptoms, depressed mood, relationships, activities of daily living, living conditions and social activities, and there is a scale for other mental and behavioural problems which might not have been covered in the other scales. The HoNOS glossary gives details on the ratings for each scale, where scores range from 0 to 4 , indicating: 0 , no problem; 1 , subclinical problem; 2, mild clinical problem; 3 , moderate clinical problem; 4, severe clinical problem.

We observed the use of the HoNOS in assessing older persons with moderate to profound learning disabilities. In most research on the learning disabled population, 50 years is considered the threshold for ageing (Jenkins et al, 1994) and is the reason for observing patients over the age of 50 years in this study.

The pilot version 3 of the HoNOS was used, though it had been intended for use with the adult mentally ill, as specific versions for learning disability were not available at the time.

\section{The study}

All older ( $>50$ years) residents of a learning disability hospital, the Cell Barnes Hospital, St Albans, Hertfordshire were assessed using the HoNOS pilot version 3 , twice at six-month intervals. The study was carried out between June and December 1995.

The results were compared using the $\chi^{2}$ test to observe differences between the initial and second HoHOS assessments. The ratings were carried out by the same person (O.A) who received training in the use of the HoNOS at a training workshop.

Approval of the hospital's ethics committee and permission of the consultants in charge of the patients were obtained. The consent of patients and carers was also sought before each interview.

\section{Findings}

Sixty-three of the 201 residents were aged over 50 years and fulfilled our criteria of long stay ( $>1$ year in hospital). They were assessed using the HoNOS, with information obtained from carers, 
medical notes and interviews with the patients. Those assessed consisted of 32 males and 31 females, with ages ranging from 50 to 102 years (mean age of 60.8 years). Their length of admissions ranged from 12 to 61 years (mean $=41.5$ years). Fifty $(79.4 \%)$ were in the moderate to profound range of learning disability (intelligence quotient $<20-49$ ) and the rest had a mild learning disability (intelligence quotient 50-69).

The scores obtained revealed that the proportion of patients with high HoNOS scores (2-4) in both sets of results were greatest in problems with cognition, physical illnesses or disabilities, relationships and activities of daily living (Table 1). There were no significant differences between the two sets of HoNOS scores obtained in the 63 patients over a six-month period.

\section{Comment}

This study involving the use of HoNOS in assessing long-stay, learning disabled patients indicated that the four greatest problem areas were with cognition, physical health, relationships and activities of daily living. As their levels of disability were mainly in the moderate to profound range, the high scores found with problems of cognition, relationships and activities of daily living were to be expected and reflect the ability of HoNOS to assess these problems in these patients. The findings are in keeping with a larger, previous study which included most of the patients in this study using the Disability Assessment Schedule (Fernando et al, 1995). The Disability Assessment Schedule is a 44-item instrument and was designed to elicit information on abilities, disabilities and behavioural problems in persons with learning disabilities (Holmes et al, 1982). As it is a longer instrument. it gives more detailed identification of problems compared with the HoNOS.

The high proportion of patients with physical illness and disability problems in persons with learning disabilities indicate a group of individuals who are more likely to have associated physical disorders such as epilepsy than the general population (Hand, 1994). The HoNOS were able to highlight these problems in the group studied.

Our findings, of no significant difference for all of the scales at Times 1 and 2, are expected in long-stay patients whose problems have stabilised. We expect that the results would have been different if carried out on patients in an acute admission unit, where treatment should result in improvement of their problems.

Limitations of this study include poor communication skills in some patients which meant symptom ratings relied on carers' observations. We used the available version of the HoNOS at the time of the study and are aware that adaptations are being made to them for use with persons with learning disabilities. Wider use of the scales is likely to result in further modifications for these patients whose peculiar problems such as head-banging, movement disorders and ritualistic behaviour, are not well addressed. Another issue we cannot comment on is the sensitivity of the respective scales to change through worsening or improvement of problems. It is our belief that this can only be addressed through larger, long-term studies.

\section{Acknowledgements}

We acknowledge the support and statistical advice of Dr Martin Orrell, Consultant Psychiatrist/Senior Lecturer at the University College

Table 1. Comparing the proportion (\%) of 63 long-stay patients with learning disabilities who had HoNOS scores of 2-4 on each item at Time 1 and Time 2, using the $\chi^{2}$ test

\begin{tabular}{|c|c|c|c|c|}
\hline HONOS & $\operatorname{Time} 1$ & Time 2 & $\chi^{2}$ & $\boldsymbol{P}$ \\
\hline Overactive, aggressive, disruptive & 24.6 & 39.3 & 3.05 & 0.08 \\
\hline Non-accidental self-injury & 1.6 & 1.6 & & \\
\hline Problem-drinking or drug-taking & 0 & 0 & & \\
\hline Cognitive problems & 98.4 & 96.7 & 0.34 & NS \\
\hline Physical Illness or disability problems & 59 & 50.8 & 0.83 & NS \\
\hline $\begin{array}{l}\text { Problems with hallucinations and } \\
\text { delusions }\end{array}$ & 4.9 & 8.2 & 0.53 & NS \\
\hline Problems with depressed mood & 3.3 & 6.6 & 0.7 & NS \\
\hline $\begin{array}{l}\text { Other mental and behavioural } \\
\text { problems }\end{array}$ & 16.4 & 13.1 & 0.26 & NS \\
\hline Problems with relationships & 77 & 86.9 & 2 & NS \\
\hline $\begin{array}{l}\text { Problems with activities of daily } \\
\text { llving }\end{array}$ & 96.7 & 96.7 & & \\
\hline Problems with living conditions & 0 & 1.6 & 1.01 & NS \\
\hline $\begin{array}{l}\text { Problems with occupation and } \\
\text { activities }\end{array}$ & 4.9 & 1.6 & 1.03 & NS \\
\hline
\end{tabular}


London Medical School, along with the staff and patients of the Cell Barnes Hospital in St Albans, Hertfordshire.

\section{References}

ALLAN, S. \& MCGONAGLE, 1. (1997) A comparison of HoNOS with the Social Behaviour Schedule in three settings. Journal of Mental Health, 6, 117-124.

Ashaye, O., Mathew, G. \& Dhadphale, M. (1997) A comparison of older, longstay psychiatric and learning disability inpatients, using the Health of the Nation Outcome Scales. International Journal of Geriatric Psychiatry, 12, 548-522.

Fernando, L., Kohen, D. \& Mathew, G. (1995) Disability assessment of a large hospital population with a mental handicap. British Journal of Developmental Disabilities. 41, 97-104.

HAND, J. E. (1994) Report on a national survey of older people with lifelong intellectual handicap in New Zealand. Joumal of Intellectual Disability Research. 38. 275-287.
Holmes, N., Shah, A. \& Wing, L. (1982) The Disability Assessment Schedule: a brief screening device for use with the mentally retarded. Psychological Medicine, 12. 879-890.

Jenkins, R., BRooksbank, D. \& MilleR, E. (1994) Ageing in learning difficulties: The development of health care outcome indicators. Journal of Intellectual Disability Research, 38, 257-264.

Wing, J., Curtis, R. \& BeEvor, A. (1994) 'Health of the Nation': Measuring mental health outcomes. Psychiatric Bulletin, 18, 690-691.

*Olakunle Ashaye, Senior Registrar, Mental Health Unit, Princess Alexandra Hospital, Hamstel Road, Harlow, Essex CM20 1QX; George Mathew, Consultant Psychiatrist, Cell Barnes Hospital, Highfield Lane, St Albans; and Elizabeth Rigby, Clinical Audit Coordinator, Barnet Community Healthcare NHS Trust, Colindale Hospital, Colindale Avenue, London

*Correspondence

\title{
New from Gaskell
}

\section{Safeguards for Young Minds}

\section{Young People and Protective Legislation}

\author{
Richard White, Richard Williams, Anthony Harbour and William Bingley
}

This co-publication with the NHS Health Advisory Service is concerned with aspects of the law as it applies to the welfare and protection of minors, and the management of children and adolescents in mental health services. It includes a complete update of the Concise Guide to the Children Act 1989, with a concise summary of the provisions of the Children Act. Particular issues relating to the use of the Mental Health Act 1983 with younger people and recent developments wrought by case law are also covered. Price £10.00, 84pp., 1996, ISBN $090224194 \mathrm{X}$

Available from good bookshops and from the Publications Department, Royal College of Psychiatrists, 17 Belgrave Square, London SWIX 8PG. Credit card orders can taken over the telephone (+44(0) I 7 I-235 235I, extension 146)

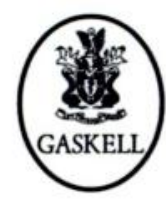

